\title{
Numerical simulation of stress distribution
}

\author{
Olga Barykina $^{1^{*}}$, Igor Fomenko ${ }^{2}$, and Oleg Zerkal ${ }^{1}$ \\ ${ }^{1}$ Lomonosov Moscow State University, Faculty of Geology, Moscow, Russia \\ ${ }^{2}$ Russian State University for Geological Prospecting, Moscow, Russia
}

\begin{abstract}
The Rogun hydropower plant is being constructed in Tajikistan, in the valley of the Vakhsh River. The construction site is located in a narrow gorge separating the Vakhsh and Surkh-Ku ridges. Most of the hydroelectric complex structures are located within a single tectonic block, which is bounded by two faults - Ionakhsh and Gulizindan, which are proximal to the Vakhsh regional fault. The study of stress distribution around the diversion tunnel was carried out by numerical simulation, which aimed to identify the stress distribution in the strongly dislocated heterogeneous rock massif before and after the tunnel creation. The underground cavity of the tunnel is a significant factor influencing the natural stress field of the rock massif. An area with critical values of the strength coefficient in the working roof, caused by the presence of a weak layer of Lower Cretaceous siltstones, is revealed in the tunnel location. The size of this area reaches two tunnel diameters. The change of stresses and their concentration around the underground working can cause deformations in the roof (collapse or rock bumps).
\end{abstract}

\section{Introduction}

The Rogun hydropower plant is being constructed in Tajikistan, in the valley of the Vakhsh River. The construction site of the Rogun HPP is located in a narrow gorge separating the Vakhsh and Surkh-Ku ridges. The left side of the gorge rises by $400 \mathrm{~m}$ and the right one by $600 \mathrm{~m}$. The average steepness of slopes is $50-60^{\circ}$ with separate steep sections. The width of the valley on the construction site at the river marks is $40 \mathrm{~m}$, along the normal reservoir water surface line is $700 \mathrm{~m}$.

\subsection{Engineering-geological conditions of the Rogun hydropower plant site}

The Rogun HPP site is confined to the junction of two major tectonic structures of Central Asia - the Afghan-Tajik depression and the southwestern Tien Shan. The articulation zone is the Vakhsh regional fault - it is considered a thrust fault by its predominant component of recent movements. At the Garmsky geodynamic testing ground, a detailed picture of displacements in the frontal part of the thrust was obtained in a series of profiles that intersect the thrust: a dip before the plane of thrust comes to the surface up to $5 \mathrm{~mm} /$ year, a shaft-like rise of the thrust front at a rate of $4-15 \mathrm{~mm} / \mathrm{year}$. This establishes the flakiness of the thrust

*Corresponding author: ol.barykina2011@yandex.ru 
[7]. At present, creep movements are recorded along the fault, and earthquakes of up to 9 magnitude are associated with movements along the fault.

A large ancient (middle Neopleistocene), river valley, inherited at present by the modern valleys of the Surkhob, Vakhsh, and Obi-Garm rivers, was excavated along the zone of the regional Vakhsh fault. The ancient valley is made of loose formations, mainly cobbles up to $300 \mathrm{~m}$ thick. The bottom of the cobbles is located $100-150 \mathrm{~m}$ below the modern Vakhsh river mouth [6].

Most of the main structures of the hydroelectric complex (figure 1) are located within a single tectonic block, which is bounded by two faults of the second-order - Ionakhsh and Gulizindan, which are proximal to the Vakhsh regional fault. The Ionakhsh fault is the main tectonic structure of the site [1]. This fault can be traced in the upstream side along the foot of the slope of the left bank of the Vakhsh valley, crosses the river within the upper toe and, passing to its right bank, goes deep into the massif of the Vakhsh ridge. It is a steeply dipping ramp. The incidence angle of the fault plane in the southwest direction is $80^{\circ}$. Movement velocities along the Ionakhsh fault are $2 \mathrm{~mm} / \mathrm{year}$, and along fault No 35 are $1 \mathrm{~mm} /$ year. Tectonic lenses of these faults, uncovered on the surface by erosion processes, are "squeezed" out of the massif at a rate of $2-3 \mathrm{~mm} /$ year.

Geologically, almost all of the main structures of the hydroelectric complex are located within a single monoclinal [6]. The monoclinal is composed of Upper Jurassic and Cretaceous sediments, which, like the Ionakhsh fault, fall in the downstream direction at angles of $65-75^{\circ}$. Upper Jurassic sediments are represented by halite with the inclusion of small fragments of terrigenous formations. Mudstones overlie rock salt about $20 \mathrm{~m}$ thick. The steeper dip of the Ionakhsh fault plane compared to the monoclinal rocks causes the salt layer to increase in thickness with depth (about $15 \mathrm{~m}$ per every $100 \mathrm{~m}$ of depth), which gives it a wedge shape with the top truncated as a result of dissolution. On the surface, Upper Jurassic argillites are exposed; the salt dissolution boundary is located $35 \mathrm{~m}$ below the Vakhsh river edge. The Lower Cretaceous [6] red-colored terrigenous sediments, $1150 \mathrm{~m}$ thick, are represented by irregularly interbedded sandstones, siltstones, and less frequently mudstones. In the upper and partially in the lower pools, Upper Cretaceous variegated formations are exposed - interstratified strata of mudstones, limestones with interlayers of sandstones, and gypsums.

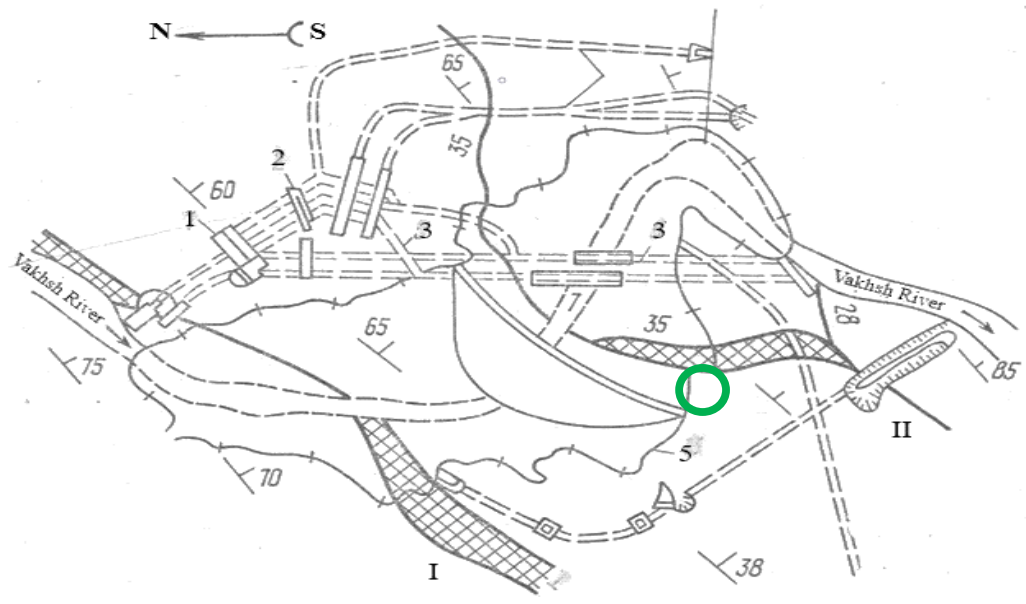

Fig.1. Layout of Rogun HPP structures (based on materials from the Institute "Gidroproekt"; [4]). Legend: 1 is intake channel, 2 is shaft; 3 is tailrace tunnels; 4 is tectonic faults with fracture zones (I Ionakhsh, II - fault No. 28 and No. 35), 5 is dam contour; green circle indicates the study area 
Quaternary friable deposits within the territory under consideration are represented by small areas but rather thick (up to $20 \mathrm{~m}$ ) fan-talus. In the river channel, the thickness of modern alluvial boulder and cobble deposits does not exceed $8-12 \mathrm{~m}$.

The bases of most constructions are Upper Jurassic and Lower Cretaceous rocks $\left(\mathrm{K}_{1} \mathrm{kz}\right)$, sandstones, siltstones, and mudstones (with sandstones predominating), consisting mainly of quartz and feldspar fragments and falling at $70^{\circ}$ down the valley. The sandstones are dominated by carbonate and carbonate-clay cement, while the siltstones and mudstones are dominated by clay cement.

In general, both sandstones and siltstones of the Lower Cretaceous strata are tough rocks (Table 1). The Upper Jurassic argillites are somewhat weaker above the salt dissolution boundary, but below the influence of the desalination processes, they are indistinguishable from the Lower Cretaceous in bearing strength. The sandstones in the sample are practically unweathered. With the loss of natural moisture, the siltstones and mudstones are degraded to coarse, fine gravel within a few hours.

Table 1. Mechanical strength characteristics of Lower Cretaceous rocks on the Rogun HPP site based on data from $[4,5]$, (Hoek-Brown strength criterion $[6,7]$ )

\begin{tabular}{|c|c|c|c|c|c|c|c|c|c|}
\hline 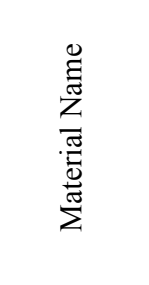 & 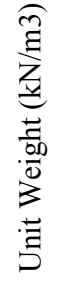 & 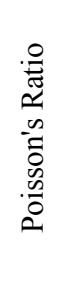 & 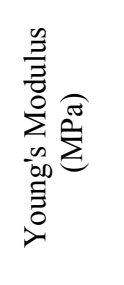 & 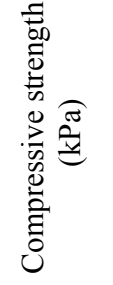 & 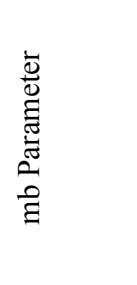 & 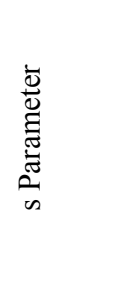 & 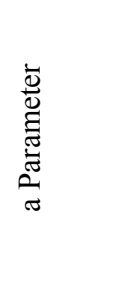 & 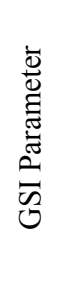 & 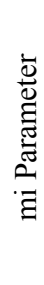 \\
\hline Sandstone & 26 & 0.3 & 6066.78 & 110000 & 1.99443 & 0.001273 & 0.511368 & 40 & 17 \\
\hline Siltstone & 27 & 0.3 & 1556.25 & 57000 & 0.480628 & 0.00024 & 0.531267 & 25 & 7 \\
\hline Mudstone & 24.4 & 0.3 & 396.55 & 5000 & 0.160736 & 0.000045 & 0.585357 & 10 & 4 \\
\hline
\end{tabular}

The rocks everywhere, except for rock salt, contain orthogonal folded fractures. In the zone of thrust influence (20 - $30 \mathrm{~m}$ for fault No35 and $5 \mathrm{~m}$ for smaller faults), a fourth, near-fault fracture system, parallel to the faults, is distinguished. In general, the fracturing of rocks is medium to strong - the size of single blocks is $15-40 \mathrm{~cm}$. The length of tectonic fractures is $1-3 \mathrm{~m}$. The cracks are open with a width of opening of $0.1-0.2 \mathrm{~mm}$, and only in the tectonic lenses the cracks have a wet clay filler of $0.1-0.5 \mathrm{~mm}$ with adhesion parameters $\mathrm{C}=0.005 \mathrm{MPa}$ and the friction angle $\varphi=28-30^{\circ}$.

Larger faults, e.g., No. 35, No. 27, and others with prevailing widths up to $20 \mathrm{~cm}$ in sections are considerably widened and form lenses of tectonically crushed masses [5]. Such faults of the third order are flanked by the Ionakhsh fault, which has a pronounced suture and a crushing zone of up to $80-100 \mathrm{~m}$. A characteristic feature of these fractures is their modern mobility, estimated from regime observations. In case of an earthquake of intensity 9, possible displacements may be up to $10-15 \mathrm{~cm}$ for tectonic fault No. 35 and several tens of centimeters for the main (Ionakhsh) fault.

Close values of strength characteristics of the main lithotypes of the Lower Cretaceous strata and approximately the same intensity of fracturing in them determine close geomechanical parameters of the massif outside the area of stress relief in the zone of exogenous processes. In weathering and unloading zones, the differences between the characteristics of the lithotypes are more noticeable; in general, geomechanical characteristics decrease, and water permeability becomes higher. 


\section{Methods}

The study of stress distribution around the diversion tunnel was carried out using numerical simulation, which aimed to identify the features of stress distribution in the strongly dislocated heterogeneous rock massif before and after the tunnel creation $[2,10]$.

To assess the stress-strain state of rocks in the massif, the following tasks were solved:

Determination of the values and distribution patterns of natural stresses in the massif (Figure 4) without taking into account the influence of underground working.

Determination of the values and patterns of stress distribution taking into account the underground working.

The calculation scheme was based on the geological section made according to the results of engineering surveys [4,5] (figure 2). The solution of the tasks was carried out by the finite element method in the Software Package RS2 (Rockscience Inc.).

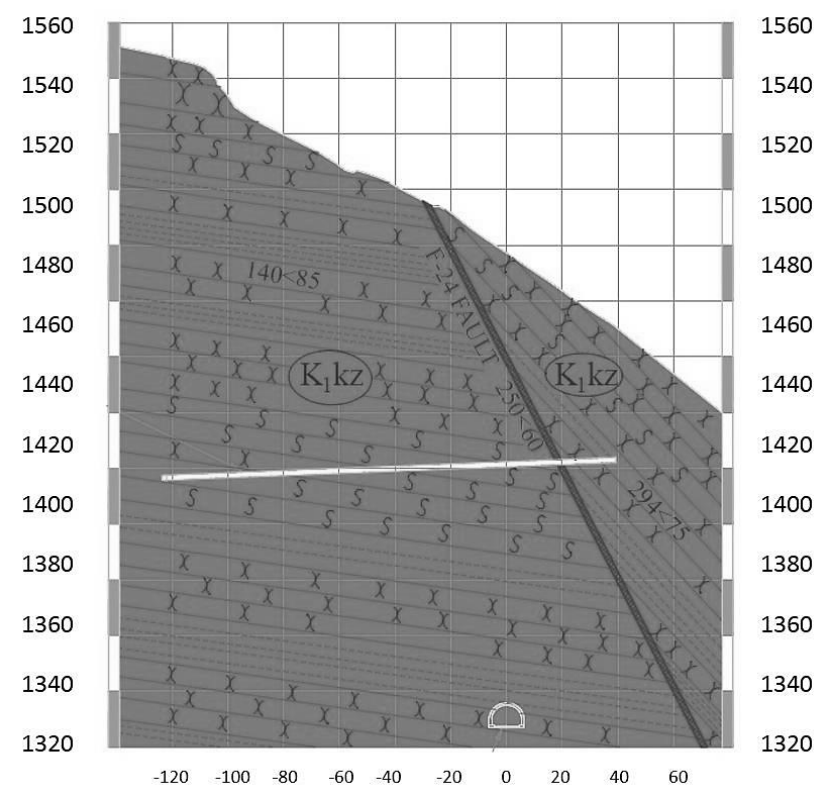

Fig.2. Geological section for simulation scheme [4]

In the considered case, the heterogeneity of the massif is caused by the layered bedding of terrigenous sandy-clayey rocks and the tectonic fault No. 27 of the thrust kinematic type.

To solve the first problem, the relief irregularities, the layered structure of the massif, and the disruption of the massif by fracture were taken into account. Additional consideration of tectonic stresses acting in the massif was not carried out at this stage. When compiling the computational scheme, we considered the dip of the layers towards the slope and the 4-m wide discontinuity No. 27 filled with friction clay with reduced values of strength and strain properties (table 1). The generalized Hoek-Brown criterion was used as the strength criterion [7, 8]. For this purpose, the refinement of the indicators of the Hoek-Brown strength criterion taken in the calculation was carried out in the RocLab Program (Rockscience Inc.), which allows the transition from the results obtained in the sample to the massif characteristics [9]. 


\section{Results and Discussions}

The final geomechanical scheme obtained from numerical simulation of natural stresses acting in the massif is shown in figure 3.

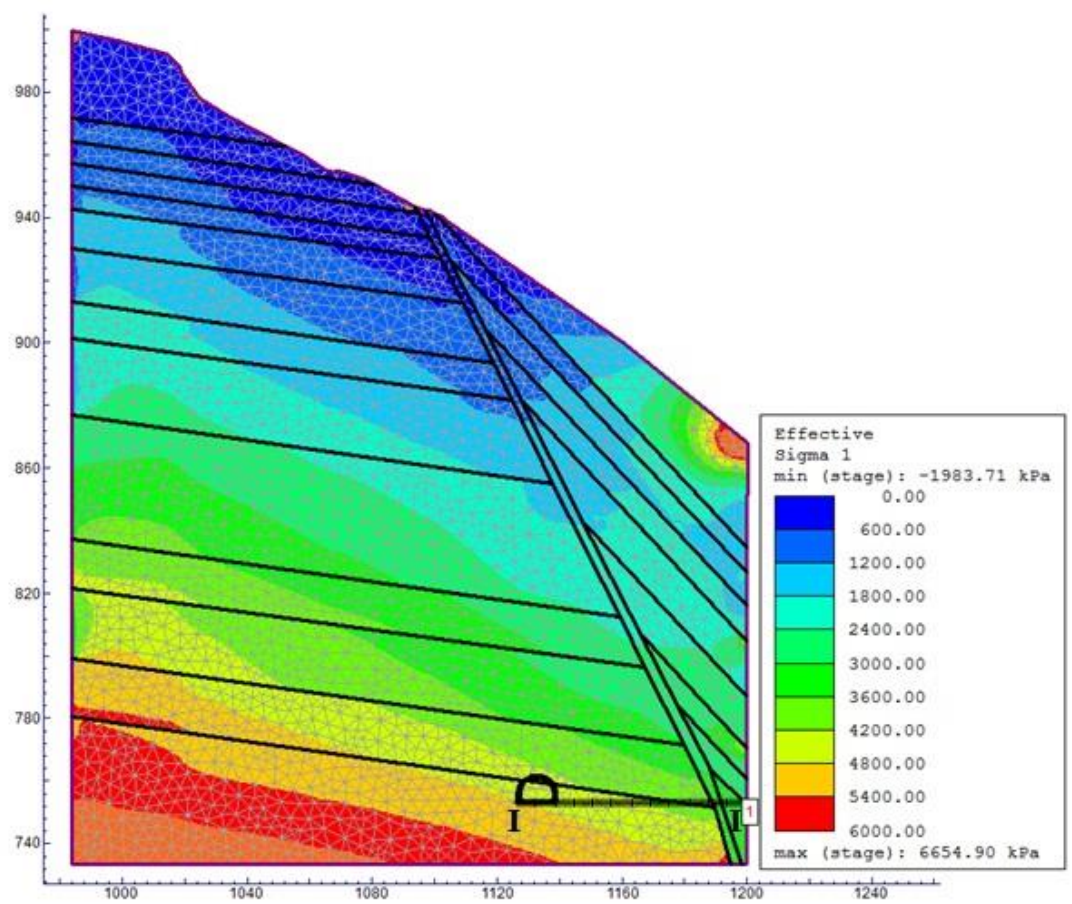

Fig. 3. Distribution of natural stresses in the rock massif of the left bank of the Vakhsh river valley before the excavation and the planned location of the tunnel.

The obtained results of simulation allow concluding the natural increase of stress values in the direction deep into the massif. Analysis of stresses variability in the direction from the slope surface deep into massif (line I - I on figure 4) showed a general smooth decrease of acting stresses to the slope surface (at a distance of $55 \mathrm{~m}$ for $1000 \mathrm{kPa}$ ), connected with stresses unloading at the erosive incision of the river valley (figure 3 ). However, at the intersection of the fault, in the two-meter zone of tectonic disturbance, there is a sharp drop of stresses, reaching $600 \mathrm{kPa}$. At the same time, based on the results obtained, the tunneling section is located outside the area of tectonic disturbance influence on the distribution of active stresses in the massif. 


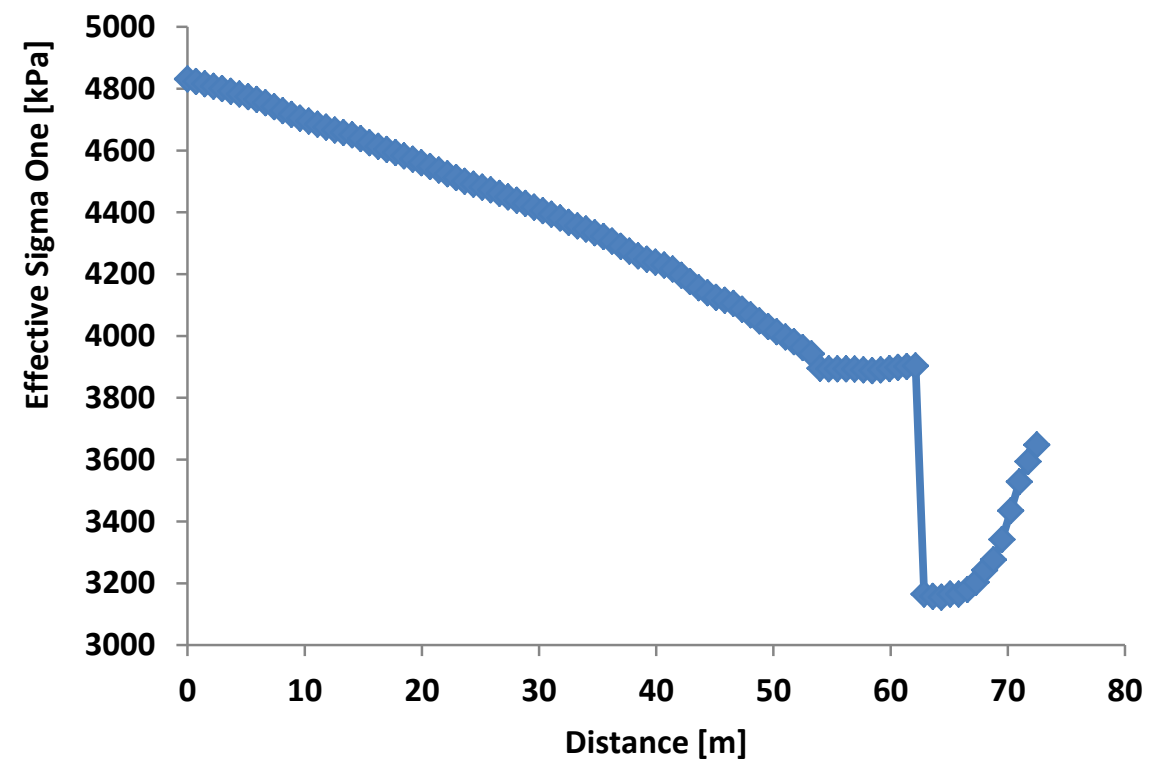

Fig. 4. Stress values $\sigma_{1}$ along the line (I - I) in figure 3, showing a sharp drop in the fault zone

At the second stage, the change of stress distribution around the tunnel was evaluated. The strength coefficient was used as a criterion for assessing the state of the massif around the excavation. The strength coefficient is defined as the ratio of rock strength to the value of acting stresses $S_{\max } / S$. All three main stresses influence the strength coefficient $\left(\sigma_{1}, \sigma_{3}\right.$, and $\sigma_{\mathrm{Z}}$ ), so the strength coefficient can be considered a three-dimensional characteristic of the massif. If the coefficient of strength is greater than 1 , it means that the strength of the material is greater than the induced stress; if less than 1, the stress exceeds the strength of the material.

The underground cavity of the tunnel is a significant factor influencing the change in the natural stress field of the rock massif considered in figure 3. In turn, the change of stresses and their concentration around the underground working can cause deformations in the form of roof collapse or rock bump.

The character of the stress field forming around the working (figure 5) depends on several factors.

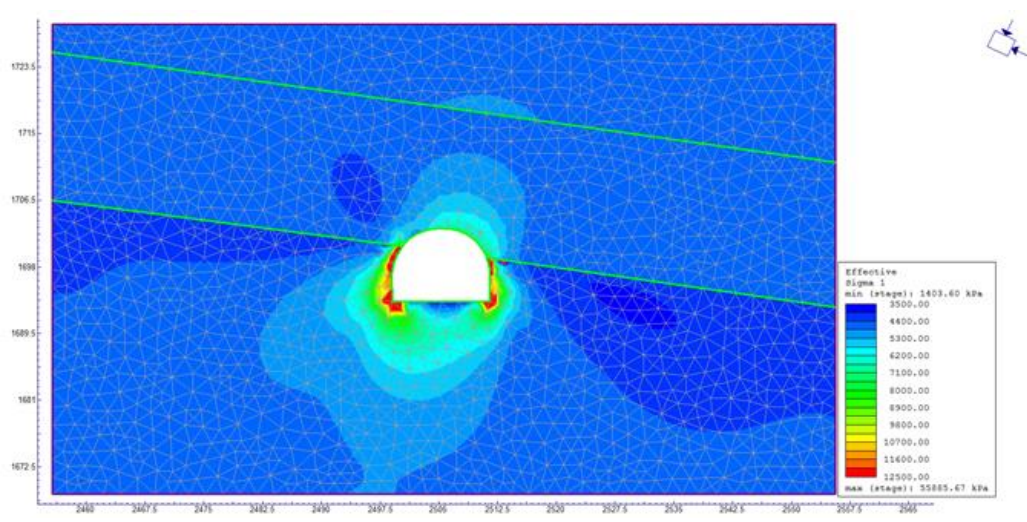

a) 


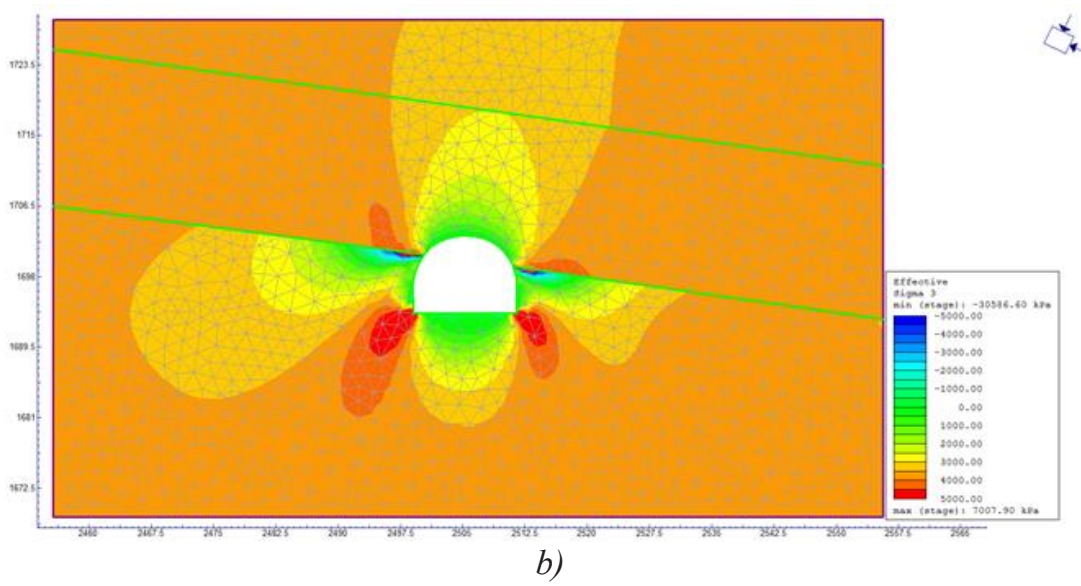

Fig.5. Distribution of stresses $\sigma_{1}(\mathrm{a})$ and $\sigma_{3}(\mathrm{~b})$, formed during the creation of underground working.

Firstly, from the values and ratios of stresses caused by the weight of rock mass and possible action of tectonic force (not considered at this stage). Second, from the peculiarities of the rock mass structure and physical and mechanical properties of rocks in the immediate vicinity of the underground working contour. Directly for the analyzed massif, such features are:

The analysis of obtained results shows the character of stresses distribution in the rock massif in the tunnel excavation section. The negative role of lower cretaceous siltstones, which lie in the tunnel roof, is clearly seen in figure 5. The calculations show (figure 6) that tunnel boring of the given geometry and size leads to a considerable decrease of strength factor, which value in the excavation roof decreases 4 times. The obtained result of modeling indicates the potential instability of this part of the massif.

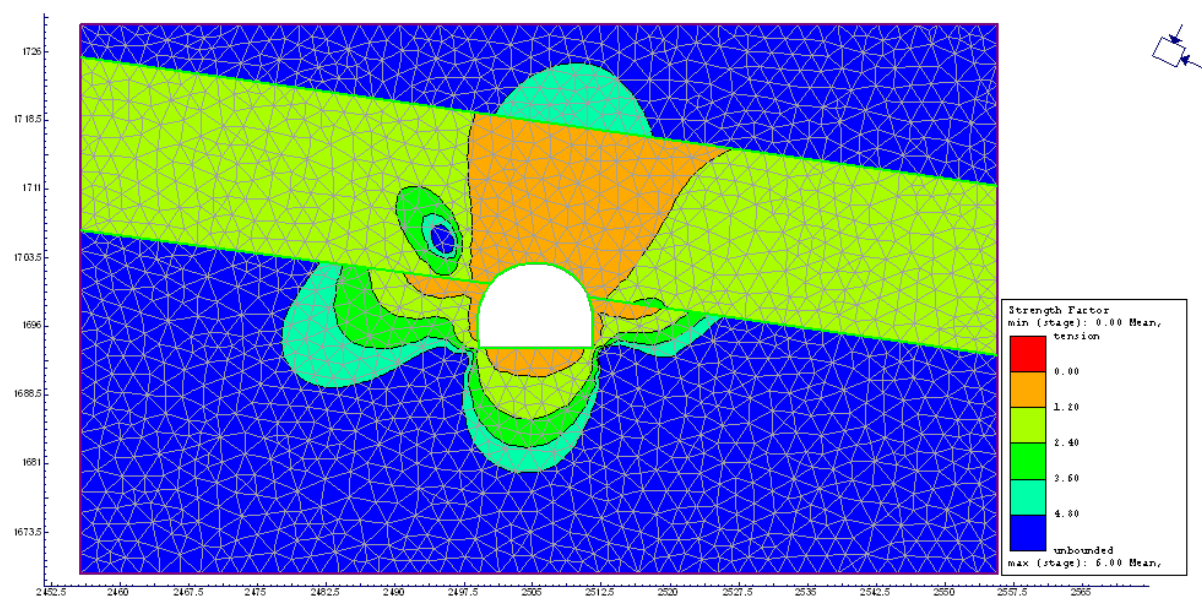

Fig. 6. Ratio of soil strength to the value of effective stresses (strength coefficient) in the massif containing the underground working

The maximum calculated dimensions of the influence zone at the top of the working reach two tunnel diameters, predetermined by the thickness and structure of the weak dislocated siltstone layer. The dip at the base and walls of the working is much smaller and does 
not exceed $1 / 3$ of the tunnel diameter. Stress concentrations are fixed in the corners of the lower part of the tunnel.

\section{Conclusions}

The following conclusions can be made based on the results of the conducted research:

1. Engineering-geological conditions of Rogun HPP construction site are characterized by complex geological and seismotectonic conditions, with the location of underground structures in the massif of dislocated Lower Cretaceous sandstones and siltstones with several systems of cracks and active faults.

2. The used software package RS2 (Rockscience Inc.) allows predicting the location of areas of increased stress in the rock massif near the underground working.

3. The calculations showed a stress drop in the fault zone located close to the tunnel.

4. Underground working (tunnel) significantly changes the picture of stress distribution in the massif.

5. An area with critical values of the strength coefficient in the working roof, caused by a weak layer of Lower Cretaceous siltstones, is revealed in the tunnel location. The size of this area reaches two-cavity diameters.

6. Within this area, during the construction of underground structures of Rogun HPP, unfavorable phenomena (rock bumps, shooting of rocks, falls, etc.) may occur.

7. In the future, it is planned to study the influence of compressive tectonic force and faulting on stress redistribution.

\section{Acknowledgements}

We would like to thank Rocsience Inc. for providing the academic software license (the Department of Engineering Geology of Russian State University for Geological Prospecting is a member of the Rocsience Academic Bundle Program).

\section{References}

1. Barykina O.S, The study of tectonic faults in engineering geology Proc. of Int. Symp. on Engineering Geology and the Environment (Athens) (Rotterdam: A.A. Balkema/Rotterdam/Brookfield) pp 45-48. (1997)

2. Kalinin E.V, Barykina O.S and Panasyan L.L, Mathematical-numerical modeling of tectonic fault zone (Tadzhikistan) Proc. of XII IAEG Cong. Engineering Geology for Society and Territory Springer International Publishing Switzerland (6) pp. 91-93. (2015)

3. Zolotarev G.S, Engineering Geodynamics. (Edition: Moscow State University) p. 328 (in Russian). (1983)

4. Zolotarev G.S, Methods of engineering-geological researches (Edition: Moscow State University Press) p. 384 (in Russian) (1990).

5. Kolichko A.V, Engineering-geological conditions of the construction of the Rogun HPP dam. Hydrotechnical Construction. (Energoizdat).10. pp. 11-15 (in Russian) (1981).

6. Nesmeyanov S.A, Engineering Geotectonics (Moscow: Nauka) p. 780 (in Russian). (2004)

7. Fomenko I.K, Kurguzov K.V, Zerkal O.V. and Sirotkina O.N, Setting soil strength parameters for slope stability calculations. In Geotechnics Fundamentals and Applications in Construction: New Materials, Structures, Technologies and Calculations vol 2 of Proceedings in Earth and geosciences (CRC Press/Balkema 
Leiden: The Netherlands) pp. 59-64. (2019)

8. Hoek E and Brown E T Empirical strength criterion for rock masses, J. Geotech. Geoenviron Eng. Div. ASCE 106 pp. 1013-1035. (1980)

9. Hoek.E, Carranza-Torres C.T and Corkum.B, Hoek-Brown failure criterion-edition. In: Proc. of the 5th North American Rock Mech. Symp. (Toronto Canada) (1). pp. 267-273. (2002)

10. Modeling of Stress Fields in Engineering-Geological Massifs, Kalinin E V, Panasyan L.L, Shirokov V.N, Artamonova N.B and Fomenko I.K, (Moscow University Press) p. 261 (in Russian). (2003). 